\title{
Dissimilar Crystal Dependence of Vanadium Oxide Cathodes in Organic Carbonate and Safe Ionic Liquid Electrolytes
}

Pedro Tartaj, ${ }^{a}{ }^{*}$ Jose M. Amarilla, ${ }^{a}$ Enrique Morales, ${ }^{b}$ and Maria B. Vazquez-Santos ${ }^{a}$

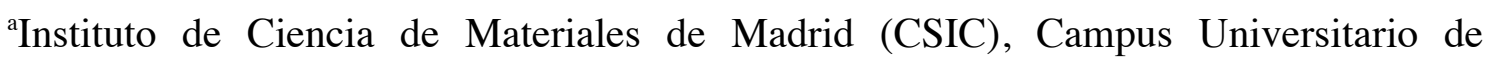
Cantoblanco, 28049, Madrid, Spain.

' Instituto de Ciencia y Tecnologia de Polimeros, CSIC, C/ Juan de la Cierva 3, 28006, Madrid, Spain.

\author{
AUTHOR INFORMATION \\ * Pedro Tartaj, Instituto de Ciencia de Materiales de Madrid (CSIC), Campus \\ Universitario de Cantoblanco, 28049, Madrid, Spain, e-mail: ptartaj@icmm.csic.es.
}


Figure S1: Thermogravimetric curve recorded in $\mathrm{N}_{2}$ atmosphere for the uniaxial vanadium oxide used as precursor of samples V200N, V350N and V400N.

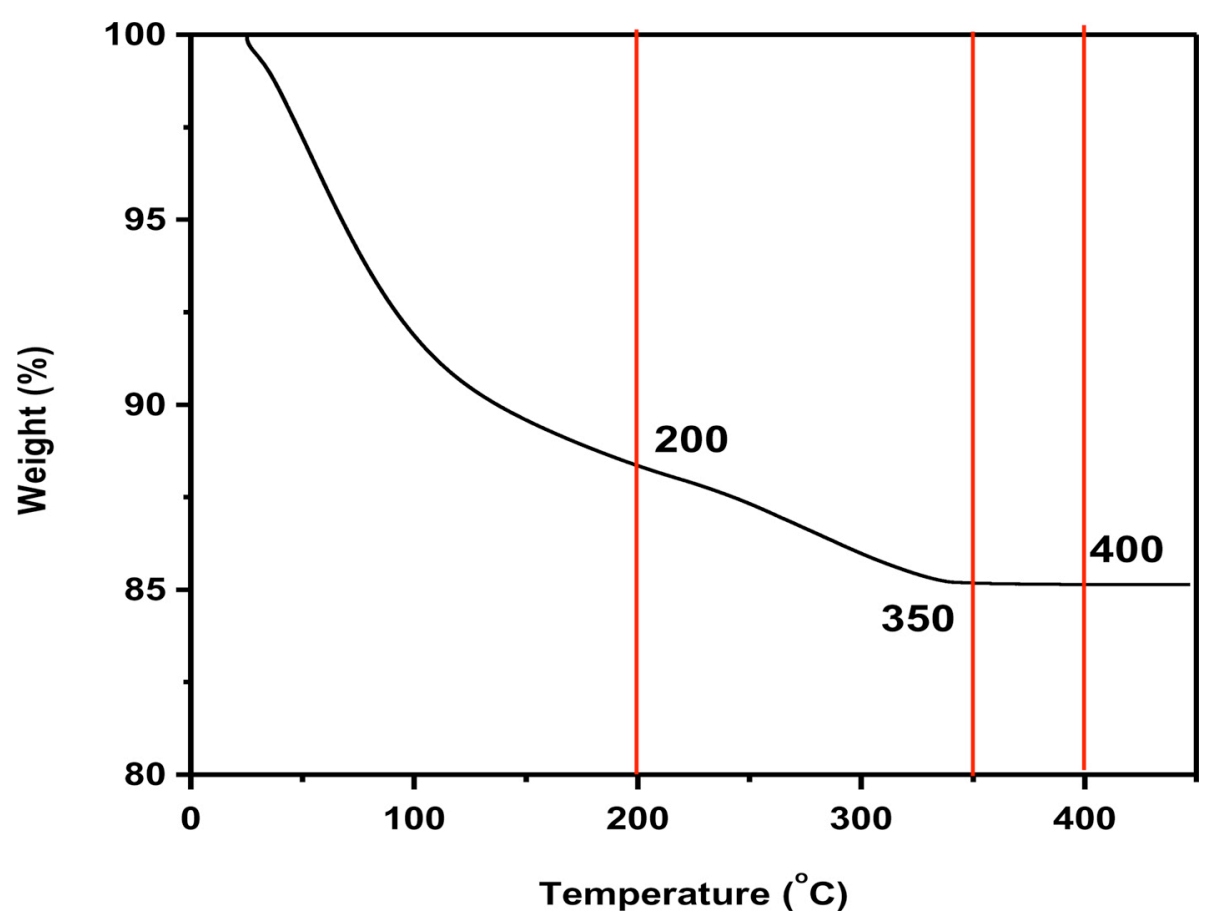

